NASA Technical Memorandum 89886

\title{
Selection of High Temperature Thermal Energy Storage Materials for Advanced Solar Dynamic Space Power Systems
}

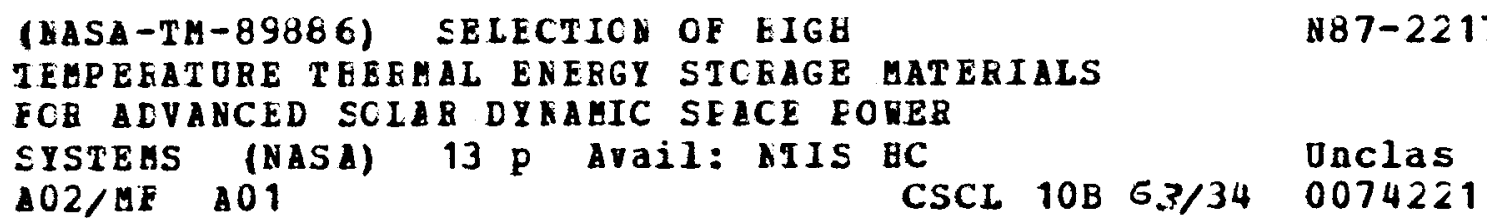

Dovie E. Lacy, Carolyn Coles-Hamilton, and Albert Juhasz

Lewis Research Center

Cleveland, Ohio

Prepared for the

22nd Intersociety Energy Conversion Engineering Conference cosponsored by the AIAA, ANS, ASME, SAE, IEEE, ACS, and AIChE Philadelphia, Pennsylvania, August 10-14, 1987 
ERRATA

NASA Technical Memorandum 89886

SELECTION OF HIGH TEMPERATURE THERMAL ENERGY STORAGE MATERIALS FOR ADVANCED SOLAR DYNAMIC SPACE POWER SYSTEMS

Dowie E. Lacy, Carolyn Coles-Hamilton, and Albert Juhasz August 1987

Page 3, reference 1: Title should read, "Impact of Thermal Energy Storage Properties on Solar Dynamic Space Power Conversion System Mass,".

Page 4, reference 7, line 2: Properties should be Properties. 


\section{SELECTION OF HIGH TEMPERATURE THERMAL ENERGY STORAGE MATERIALS FOR ADVANCED SOLAR DYNAMIC SPACE}

\section{POWER SYSTEMS}

Dovie E. Lacy, Carolyn Coles-Hamilton, and Albert Juhasz

National Aeronautics and Space Administration

Lewis Research Center

Cleveland, Ohio 44135

\section{Abstract}

Under the direction of NASA's Office of Aeronautics and Space Technology (OAST), the NASA Lewis Research Center has initiated an in-house thermal energy storage program to identify combinations of phase change thermal energy storage media for use with a Brayton and Stirling advanced solar dynamic (ASD) space power systems operating between 1070 and $1400 \mathrm{~K}$. A study has been initiof ated to determine suitable combinations of thermal $\stackrel{m}{m}$ energy storage (TES) phase change materials (PCM) that result in the smallest and lightest weight ASD power system possible. To date the heats of fusion of several fluoride salt mixtures with melting points greater than $1025 \mathrm{~K}$ have been verified experimentally. The study has indicated that these salt systems produce large ASD systems because of their inherent low thermal conductivity and low density. It is desirable to have PCMs with high densities and high thermal conductivities. Therefore, alternate phase change materials based on metallic alloy systems are also being considered as possible (TES) candidates for future ASD space power systems.

\section{Introduction}

Solar dynamic systems are actively being studied as a means of providing heat and electrical power for space applications. Advanced Solar Dynamic (ASD) power systems offer the potential for efficient, lightweight, relatively compact and long-lived space power systems applicable to a wide range of power levels ( 3 to $300 \mathrm{kWe}$ ), and a wide variety of orbits. Thermal energy storage (TES) will be required by these ASD power systems to provide power to the heat engine during solar eclipse. The latent heat TES concept that will be discussed in this paper results from a solid to liquid phase change which offers a lightweight and direct method of providing the heat engine with a uniform heat source. While many critical technology issues exist for ASD power systems, finding an efficient means of energy storage is presently the least well defined and understood. Under the direction of NASA's Office of Aeronautics and Space Technology (OAST), NASA Lewis has initiated an advanced solar dynamic testing and development program. The goals of this in-house program are to identify and select high temperature (1025 to $1400 \mathrm{~K}$ ) phase change thermal energy storage materials which will yield light weight, compact and efficient solar dynamic Brayton and Stirling space power systems with an operational life of 7 to $10 \mathrm{yr}$.

Literature surveys and analytical screening has been performed to identify PCM systems with heats of fusion greater than $400 \mathrm{~kJ} / \mathrm{kg}$. Comparisons have been made between salt and metallic PCM systems and it was found that the metallic PCMs produced the smallest and lightest weight
ASD systems because of their higher thermal conductivities and densities. This paper will detail the methods used to identify and select candidate PCMs for advanced solar dynamic space power systems. Also, the effects of PCM selection on a $35 \mathrm{kWe}$ Closed Brayton Cycle (CBC) and a Free Piston Stirling Engine (FPSE) power system will be discussed.

\section{Analytical Screening}

The primary focus of the in house "Advanced Solar Dynamic Systems Code," is to determine the impact of the thermophysical properties of the selected PCMs on the power conversion systems (PCS) mass and performance. Although, selection of PCMs with high melting points will increase the system efficiency of a stirling or Brayton power system, the system mass was found to also be sensitive to other thermophysical properties of the PCM. The computer systems code used in this study will give the minimum system mass for a Brayton and Stirling power system operating at the melting point of various PCMs. 1 The goal of the systems effort is to identify systems with specific weights less than $60 \mathrm{~kg} / \mathrm{kWe}$ for LEO based service.

Receiver Considerations

As shown in $\mathrm{Fig.} 1$, the heat receiver contributes greatly to the mass of a solar dynamic power system. A typical solar dynamic heat receiver is shown in Fig. 2(a) and a detail of one PCM/working fluid tube is shown in Fig. 2(b). The study was done using three salt based PCMs ( $L i F, L i F-C a F_{2}$, $\mathrm{NaF}$ ) and two metallic PCMs (Mg-Si and $\mathrm{Ge}$ ) selected from the initial literature survey. Figs. 3 and 4 show the system masses of a $35 \mathrm{kWe}$ Brayton and a 35 kWe Stirling PCS using both salt and metal PCMs. One critical difference in the masses of the salt and metal systems is the sizing of the heat receiver cavity. It is desirable to have uniform flux distribution within the cavity. Therefore, the receiver was sized by the diameter and spacing of the storage tubes based on a reasonable maximum allowable flux. The larger receiver of both cavities was used in the analysis.

One characteristic of salt PCMs is low thermal conductivity while the metallics are very good conductors. Because of the high thermal conductivities of the metal PCMs, higher solar fluxes $c$ an be tolerated within the cavity resulting in a smaller heat receiver, see Fig. 5(a). To improve the thermal conductivity of the salt system fins and reflectors are required to evenly distribute the solar flux within the cavity, this produces a large and massive heat receiver, see $\mathrm{Fig} .5(\mathrm{~b})$.

The mass of several of the heat receiver components are directly affected by an increase and or decrease in the density and heat of fusion of the PCM. For example, if the density were 
decreased more containment material would be required and the weight of the support structure and the outlet manifold would increase. Moreover, if the heat of fusion is increased the amount of storage material required will decrease thus decreasing the receiver mass. Therefore it may be logical to assume that in order to minimize the receiver weight, a PCM with a high density and high heat of fusion or a combination of PCMs with heat of fusion values high enough to offset the mass penalty imposed by low density values must be selected.

\section{Systems Computer Code}

The computer code used in this study determines for a given peak cycle temperature the optimum temperature ratio that will give the minimum system mass for the Stirling and Brayton power systems. Moreover, the analysis for the Brayton power system further optimizes to give the pressure ratio at the minimum mass conditions.

Several assumptions were made in generating the mass models for the Brayton and Stirling (PCS) and the PCMs. Namely, steady state performance of both of these systems was assumed. It was also assumed all of the heat which is absorbed by the PCM is transferred to the PCS working fluid. The specific mass of the concentrator and heat pipe radiator were assumed to be 1.22 and $5 \mathrm{~kg} / \mathrm{m}^{2}$ respectively. The emissivity of the radiator was assumed to be 0.88 .

\section{Analytical Results}

To determine the effects of a PCM's heat of fusion and density on the mass of a Stirling PCS, a parametric study was done. In this study, the density and heat of fusion of LiF was used to assess the mass penalties associated with varying these thermophysical properties over a specified temperature range. First, the heat of fusion was varied over a range of 400 to $1200 \mathrm{~kJ} / \mathrm{kg}_{3}$ with the density being held constant at $1874 \mathrm{~kg} / \mathrm{m}^{3}$. As shown in Fig. 6 , the system mass decreases with increasing heats of fusion evaluated at a constant density. Similarly, the system mass decreases with increasing density when evaluated using a specified heat of fusion (Fig. 7). In both figures, it should be noted that the rate of change in system mass is less at the higher heats of fusion and densities.

Figure 8 shows different scenarios of the same system evaluated using combinations of PCMS with low, medium, and high densities with high and low heats of fusion. Using mass as the selection criterion, it is evident that the system with the low density and low heat of fusion has a high mass. Moreover, the system with high heat of fusion and density is the least massive. The figure also indicates that there are combinations of the heats of fusion and the density where the system mass is practically the same. Therefore, one of the key factors that will limit the ability to identify systems with low masses is the selection of PCMs with high heats of fusion and densities or with the right combinations of thermophysical properties such as thermal conductivity.

Mass savings of a power system can be substantial when selecting PCM systems with both high density and high heats of fusion. Figure 9 shows that significant weight reduction can be achieved by using the ASD systems over the state of the art
(SOA) systems and Space Station Technology. 2 To date LiF has been identified as the best salt system for achieving a lightweight system because of its high heat of fusion. Yet, this study indicates that metal systems produce lightweight ASD systems because of the higher thermal conductivities and high densities.

Although the preliminary analysis of these systems appear promising, the issue of transferring heat into and out of the storage material and containment of these PCM systems have yet to be addressed.

\section{Thermophysical Property Determination}

As indicated in the previous section, the thermophysical properties of interest to this program include heat of fusion, thermal conductivity and density. To date, literature searches and other sources such as, universities and government labs have indicated that the thermophysical properties are well defined for pure salts but not for eutectic salts or metallic alloys.

NASA Lewis has the capability to determine the heat of fusion. Table 1 shows the estimated heat of fusion for several fluoride salt mixtures in the 1025 to $1400 \mathrm{~K}$ temperature range. The heat of fusion for many of the fluoride salts has now been experimentally verified by differential scanning calorimetry (DSC). Table 2 shows the heat of fusion of several metallic alloys also with melting points between 1025 and $1400 \mathrm{~K}$. Many heat of fusion values for these metallic alloys have been taken from Barin and Knack. 3

Other thermophysical properties which must be considered to determine the PCMs effect on the ASD system are thermal diffusivity and specific heat. Currently an in-house capability is being developed to determine density and thermal conductivity, and the capabilities of several laboratories throughout the United States are being investigated as possible sources for determining the specific heat and or the thermal diffusivity of the selected PCMs.

\section{Technical Issues}

The systems code has identified two types of phase change thermal energy storage systems with the potential of meeting the lightweight and high performance requirements imposed by the ASD power system. However, the low thermal conductivity of the salt systems and the containment and compatibility issues associated with both must be addressed.

\section{Thermal Conductivity Enhancement}

As previously stated one inherent characteristic of the salt PCMs is low thermal conductivity which is currently being enhanced by fins and reflectors and results in a large and massive ASD power system. One approach that can be used to enhance the thermal conductivity is presently being investigated at NASA Lewis. In this method, if the thermal energy storage canisters of the heat receiver shown in $\mathrm{Fig}$. 10 are filled with a matrix of high thermal conductivity fibers, such as graphite, then significant increases in thermal conductivity are possible. The location of the fibers with respect to the thermal energy storage 
salt is critical to both the thermal conductivity enhancement as well as the location of the voids that form on freezing. If the fibers are wetted by the phase change liquid in specific locations then enhanced thermal conductivity can be maintained. For example, with the addition of as little as $4 \&$ (by volume) of chopped P-100 graphite fibers or vapor grown fibers, the thermal conductivity of LiF should increase by a factor of 2 to 6.

\section{Containment and Compatibility}

Initial compatibility screening has concluded that mild steel, pure nickel and $\mathrm{Nb}-12 \mathrm{r}$ have relatively good corrosion resistance in molten fluoride salts. 4 Unfortunately, only Nb-1Zr possesses some measure of creep strength at elevated temperatures. However, it is a refractory metal alloy which requires special handling and fabrication techniques for successful employment. There is therefore much reluctance to use this type of material. Ideally the strength of the containment vessel should be sufficient to withstand the stresses developed during melting of the solid PCM. Many of the fluoride salts have very large expansions and volume changes upon melting for example, LiF increases in volume about 30 percent when melted. Such behavior could prove disastrous if trapped solid is melted, because the mechanical forces resulting from the volume change could breech the containment vessel wall. Throughout its life the heat receiver's TES unit will be subject to tens of thousands of freeze-thaw cycles under microgravity conditions which pose $i 11-$ defined solidification and remelting conditions. It is desirable for the containment vessel to possess adequate strength to cause the solid salt to fracture as opposed to itself. For this to be the case designers must have knowledge of the strength of the PCMs more specifically the salts because of the large volume changes they experience upon melting.

Based on the apparent ability of essentially pure $\mathrm{Fe}, \mathrm{Nb}$ and $\mathrm{Ni}$ to resist attack, it is possible that an alloy containing only these three elements would also be resistant to the molten salts. This offers the potential for developing alloys with inherent high temperature strength, for they can be built on the $\mathrm{Ni}-\mathrm{Ni}{ }_{3} \mathrm{Nb}$ system (with various amounts of $\mathrm{Fe}$ ) that exhibits behavior similar to $\mathrm{Ni}-\mathrm{Ni} 3 \mathrm{Al}$ which forms the basis for nickel superalloys.

Although, metallic alloys based on $\mathrm{Si}$ and $\mathrm{Ge}$ possess excellent thermophysical properties, they react with all metals at high temperature and rule out metallic alloys as suitable container materials. Ceramic materials such as $\mathrm{SiC}$ and $\mathrm{Si}_{3} \mathrm{~N}_{4}$ are possible candidates for containment materials, and as indicated by Ref. 5 research is currently being conducted to produce a Si containment shell on a Si-base eutectic alloy sphere. It is evident to all working in the area of containment for $\mathrm{Si}$ and Ge-based alloys that much developmental work needs to be done to find suitable container materials.

Prior to the final selection of a PCM for the ASD power system, long term (5000 to $10000 \mathrm{hr}$ ) compatibility testing with potential containment materials must be conducted. Thus, the selection of a phase change thermal energy storage material for ASD power systems is based on analytical and metallurgical screening.

\section{Concluding Remarks}

A study has been initiated to determine how PCM thermophysical properties affect the mass and size of an ASD power system. This study has shown that high temperature, high heat of fusion and high density phase change thermal energy storage materials must be utilized in order produce small and lightweight ASD systems. To date salt and metal phase change systems have been investigated. As a result of the higher thermal conductivity and density of the metallic phase change systems, as compared with the salt systems, smaller ASD systems were produced.

A literature survey to determine the thermophysical properties of the desired PCMs has indicated that such information is not readily available, or that it does not exist. Therefore, capabilities are being developed in-house to determine the density and thermal conductivity of the PCMs and other sources are currently being investigated as possible sources for determining the specific heat and or thermal diffusivity.

There are several technical issues associated with the PCMs identified as possibly being able to meet the lightweight and minimum mass requirements of NASA Lewis' ASD program. For the salt PCM the major issue is low thermal conductivity and to this end an in-house program is under way to investigate the possibilities of enhancing the thermal conductivity with graphite fibers. Another area of concern for both the salt and the metal systems is containment and in the near future a containment development program will be undertaken. For the salt systems a series of $\mathrm{Ni}-\mathrm{Ni} 3 \mathrm{Nb}$ alloys containing varying amounts of iron will be investigated and for the $\mathrm{Si}$ and Ge-based metallic systems ceramic and other new technologies will be explored.

\section{References}

1. Juhasz, A., Coles, C., and Lacy, D., "Analysis of Thermophysical Properties for Advanced Solar Dynamics," AIAA Paper 87-9442, Aug. 1987.

2. Brandhorst, H.W. Jr., Juhasz, A.J., and Jones, B.I., "Alternative Power Generation Concepts for Space," NASA TM-88876, 1986.

3. Barin, I. and Knacke, 0., Thermochemical Properties of Inorganic Substances, Springer-Verlag, New York, 1973.

4. Misra, A.K. and Whittenberger, J.D., "Estimated Heats of Fusion of Fluoride Salt Mixtures Suitable for Thermal Energy Storage Applications," NASA TM-87320, 1986.

5. Misra, A.K. and Whittenberger, J.D., "Identification of Salt-Alloy Combinations for Thermal Energy Applications in Advanced Solar Dynamic Power Systems," NASA TM-88889, 1986.

6. Misra, A.K., "Fluoride Salts at Phase Change Materials for Thermal Energy Storage in the Temperature Range $1000-1400^{\circ} \mathrm{K}$," Journal of the Electrochemical Society, 1987, submitted for publication. 
7. Bukhalova, G.A., Berezhnaya, V.T., and Okol'chishena, N.E., "Some Propertires of Compounds of the Type $M_{M} I_{F_{3}}$," Russian Journal of Inorganic Chemistry, Vol. 14, No. 7, July 1969, pp. 917-921.
8. Beardmore, P., Howlett, B.W., Lichter, B.0., and Bever, M.B., "Thermodynamic Properties of Compounds of Magnesium and Group IVB Elements," Transactions of the Metallurgica 1 Society of AIME, Vol. 236, No. 1, Jan. 1966, pp. 102-108.

TABLE 1. - PHASE CHANGE TES CANDIDATES

(FLUORIDE SALTS) 1025 TO $1400 \mathrm{~K}$

\begin{tabular}{|c|c|c|}
\hline $\begin{array}{l}\text { Salt } \\
\text { moles }\end{array}$ & $\begin{array}{c}\text { Melting } \\
\text { temperature, } \\
K\end{array}$ & $\begin{array}{l}\text { Heat of } \\
\text { fusion, } \\
\mathrm{kJ} / \mathrm{kg}\end{array}$ \\
\hline $\mathrm{LiF}-22 \mathrm{CaF}_{2}$ & 1039 & $a_{790}$ \\
\hline $\mathrm{KF}-15 \mathrm{MgF}_{2}$ & 1043 & $b_{500}$ \\
\hline $\mathrm{Li}_{3} \mathrm{~A} \mathrm{AF}_{6}$ & 1059 & 540 \\
\hline $\mathrm{NaF}-32 \mathrm{CaF}_{2}$ & 1083 & 590 \\
\hline $\mathrm{NaF}-23 \mathrm{MgF}_{2}$ & 1103 & 620 \\
\hline LiF & 1121 & $b_{1087}$ \\
\hline $\mathrm{NaF}-14 \mathrm{AlF} \mathrm{F}_{3}$ & 1161 & 539 \\
\hline $\mathrm{NaF}-27 \mathrm{CaF}{ }_{2}-36 \mathrm{MgF}_{2}$ & 1178 & 520 \\
\hline $\mathrm{CaF}-50 \mathrm{MgF} 2$ & 1253 & 610 \\
\hline $\mathrm{NaMgF}_{3}-30 \mathrm{KMgF}_{3}$ & 1259 & 641 \\
\hline $\mathrm{NaF}$ & 1268 & ${ }^{D} 790$ \\
\hline $\mathrm{NaF}-60 \mathrm{MgF}_{2}$ & 1273 & 670 \\
\hline $\mathrm{KF}-68.7 \mathrm{MgF}_{2}$ & 1281 & $a_{690}$ \\
\hline $\mathrm{Na}_{3} \mathrm{AlF}_{6}$ & 1283 & $D_{530}$ \\
\hline $\mathrm{NaMgF}_{3}$ & 1303 & ${ }^{6} 710$ \\
\hline $\mathrm{MgF}_{3}$ & 1343 & 710 \\
\hline $\mathrm{KCaF}_{3}$ & 1343 & $c_{500}$ \\
\hline $\mathrm{FeF} 2^{3}$ & 1373 & $b_{550}$ \\
\hline $\mathrm{MgF}_{2}$ & 1536 & $b_{930}$ \\
\hline
\end{tabular}

a Heat of fusion data for $\mathrm{MgF}_{2}$ obtained from in-house experimental measurements. 6

botained from Barin and Knacke's text.

CHeat of fusion data obtained by Bukhalova et al. 7

dobtained from in-house experimental measurements. 6 
TABLE 2. - PHASE CHANGE TES

CANDIDATES (METALLIC ALLOYS)

1025 T0 $1400 \mathrm{~K}$

\begin{tabular}{|l|c|r|}
\hline $\begin{array}{c}\text { Composition, } \\
\text { mole }\end{array}$ & $\begin{array}{c}\text { Melting } \\
\text { temperature, } \\
\mathrm{K}\end{array}$ & $\begin{array}{r}\text { Heat of } \\
\text { fusion, } \\
\mathrm{kJ} / \mathrm{kg}\end{array}$ \\
\hline $\mathrm{Ge}$ & 1213 & 510 \\
$\mathrm{Mg-54.5Si}$ & 1223 & $\mathrm{a}_{750}$ \\
$\mathrm{GaAs}$ & 1238 & 600 \\
$\mathrm{ZnP}_{2}$ & 1253 & 730 \\
$\mathrm{ZnAs}_{2}$ & 1288 & 450 \\
$\mathrm{Ca}_{2} 69 \mathrm{Si}$ & 1296 & $\mathrm{~b}_{1110}$ \\
$\mathrm{InP}$ & 1328 & 430 \\
$\mathrm{Mg}_{2} \mathrm{Si}$ & 1373 & 1118 \\
$\mathrm{Mg}_{2} \mathrm{Ge}$ & 1388 & 705 \\
\hline
\end{tabular}

abtained from Ref. 3.

bak Ridge National Lab data.

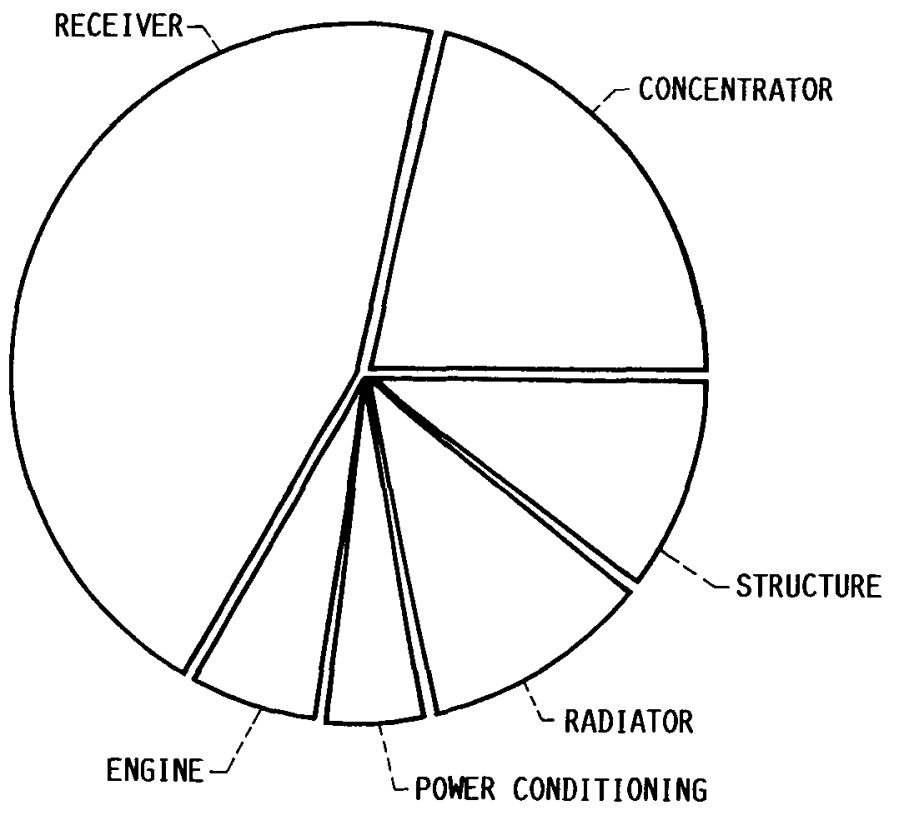

FIGURE 1. - COMPONENT BREAKDOWN OF AN ADVANCED SOLAR DYMAMIC POWER SYSTEM. 


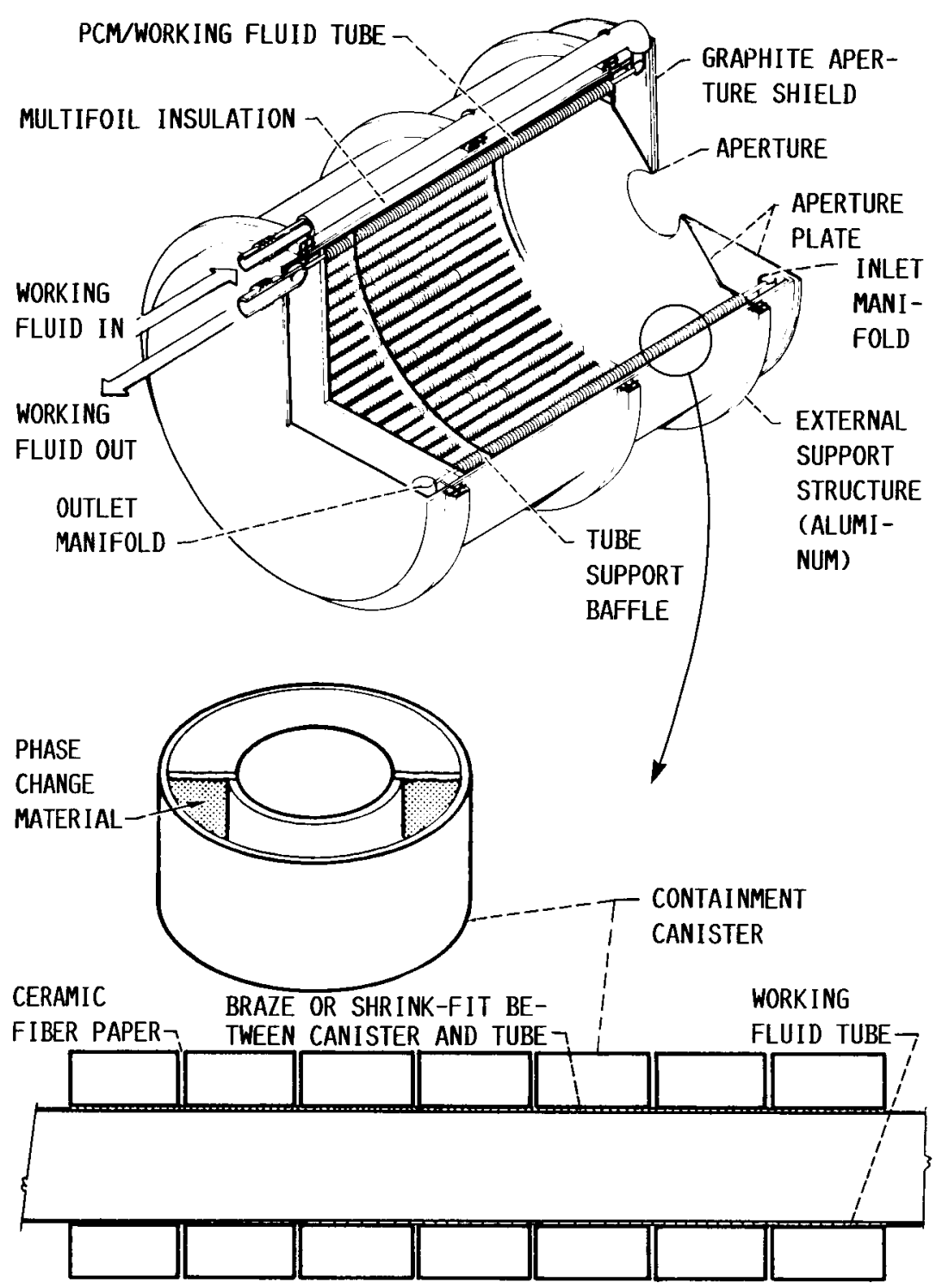

FIGURE 2. - BASELINE SOLAR DYNAMIC HEAT RECEIVER, SHOWING DETAIL OF PCM/WORKING FLUID TUBE.

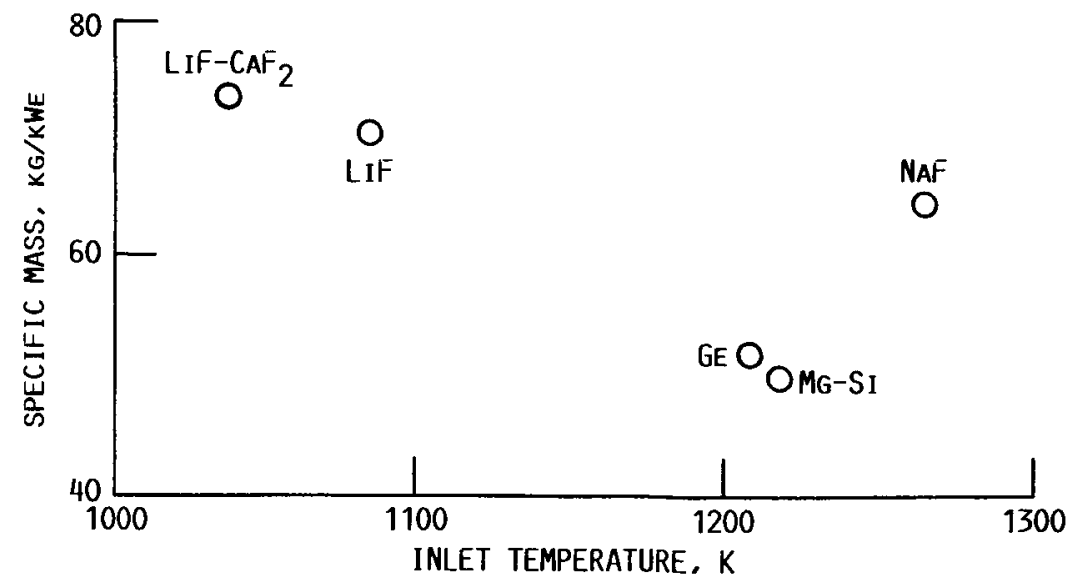

FIGURE 3. - SPECIFIC MASS AS A FUNCTION OF TEMPERATURE FOR A 35-KWE BRAYTON SOLAR DYNAMIC POWER SYSTEM USING VARIOUS PCMS. 


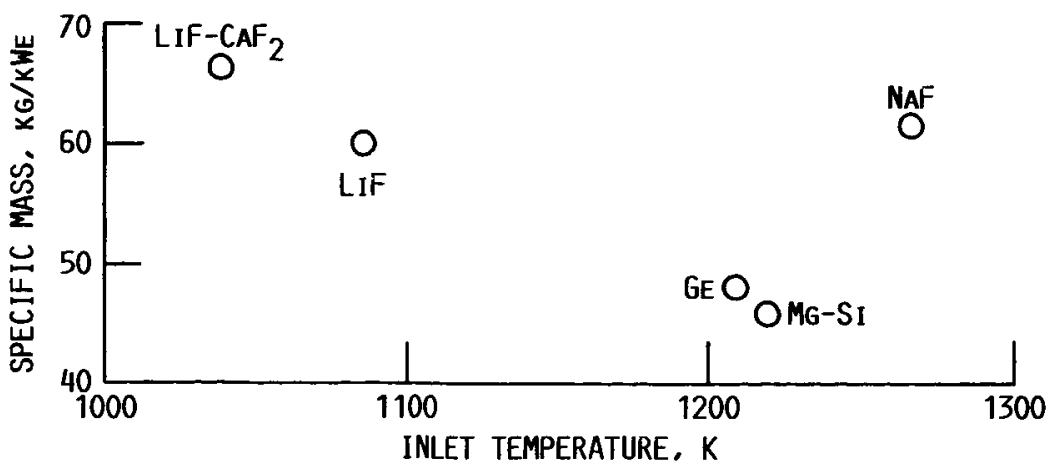

FIGURE 4. - SPECIFIC MASS AS A FUNCTION OF TEMPERATURE FOR A 35-KWE STIRLING SOLAR DYNAMIC POWER SYSTEM USING VARIOUS PCMs.
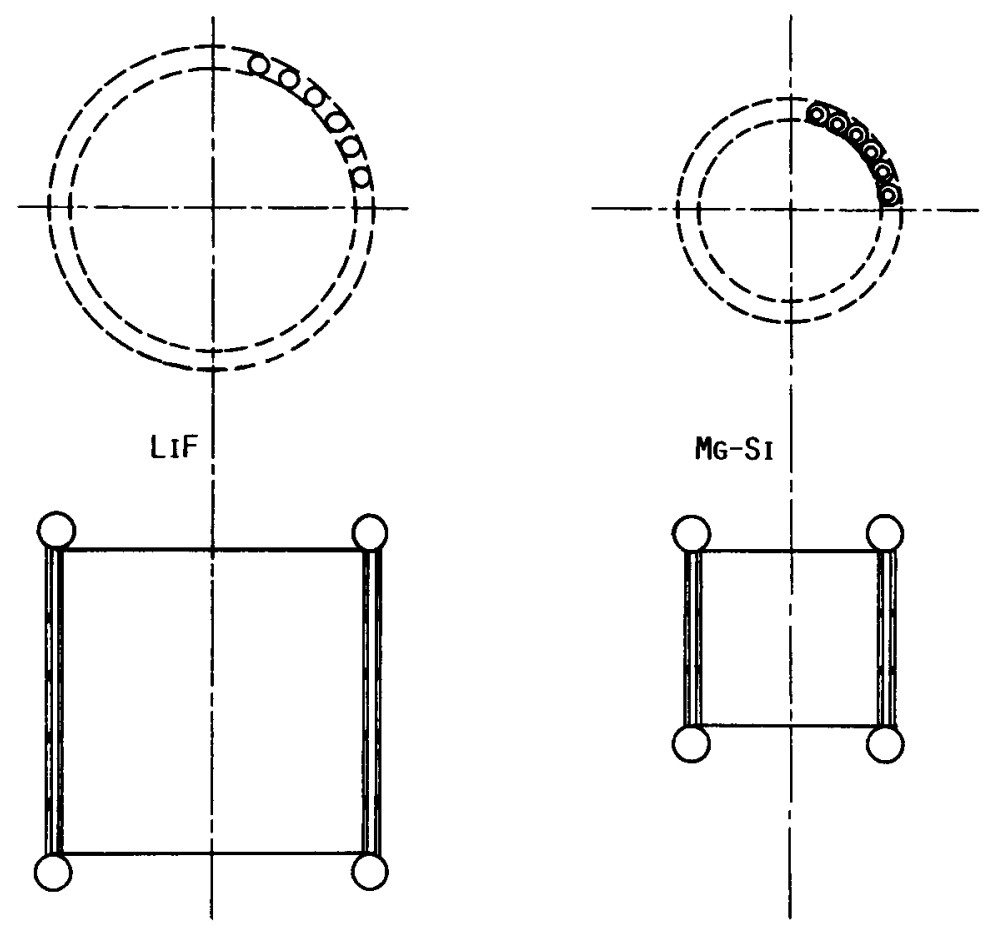

(A) RECEIVER SIZING BASED ON LIF (SALT) AND Mg-SI (METAL).

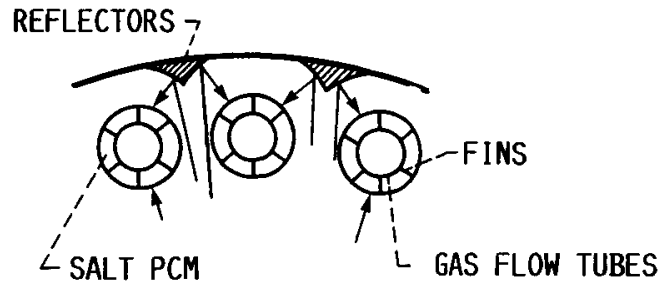

SALT

(LOW CONDUCTIVITY)

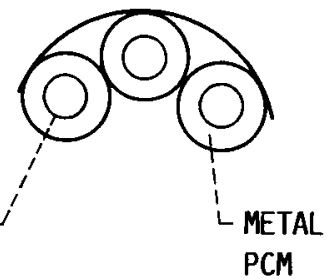

METAL (HIGH CONDUCTIVITY)

(B) EFFECTS OF LOW AND HIGH THERMAL CONDUCTIVITY.

FIGURE 5. - COMPARISON OF SALT AND METAL PHASE CHANGE THERMAL ENERGY STORAGE SYSTEMS. 


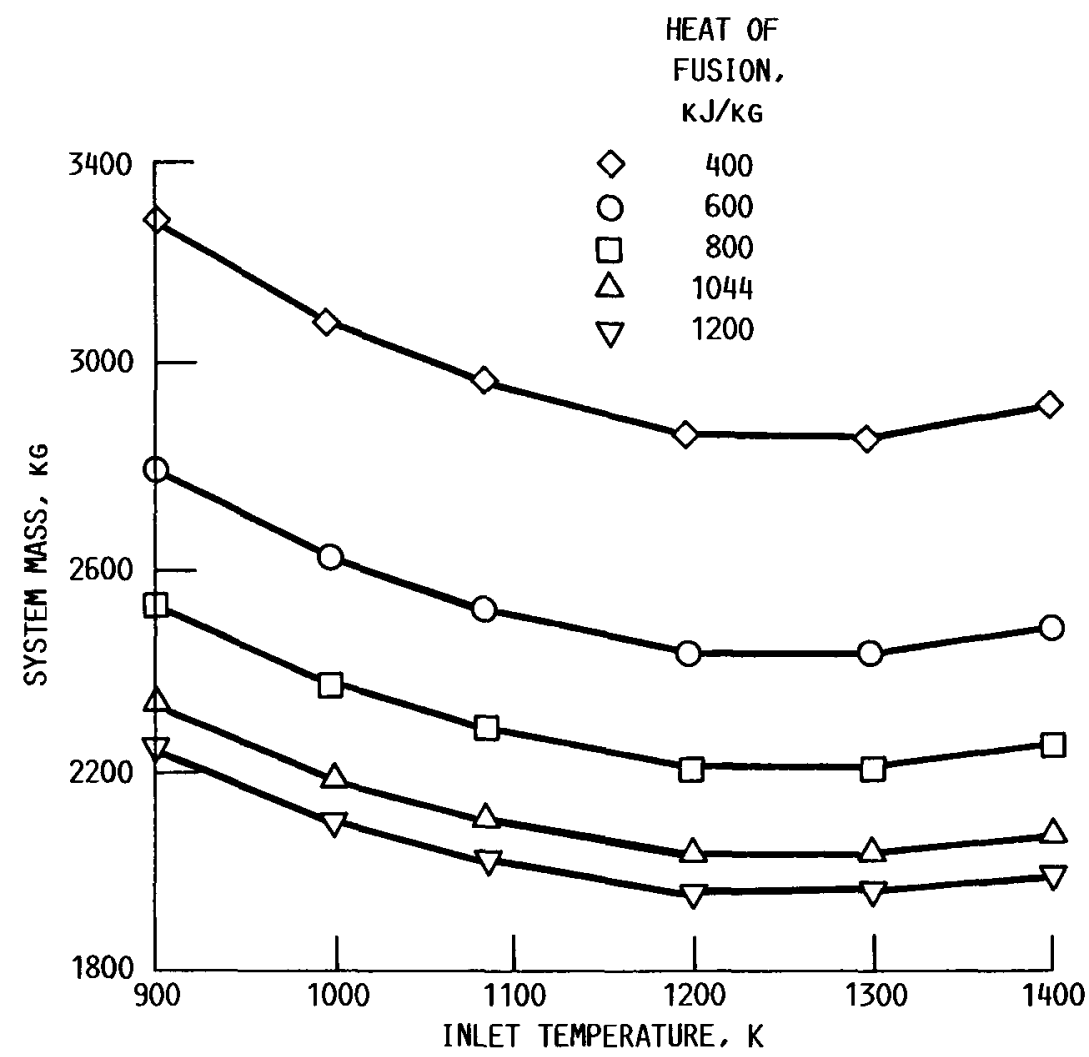

FIGURE 6. - SYSTEM MASS AS A FUNCTION OF INLET TEMPERATURE FOR A 35-KWE STIRLING SOLAR DYNAMIC POWER SYSTEM USING A SALT PCM AT VARIOUS HEATS OF FUSION. NUMBER OF TUBES, 60: NUMBER OF FINS, 6 ; DENSITY, $1874 \mathrm{kG} / \mathrm{m}^{3}$. 


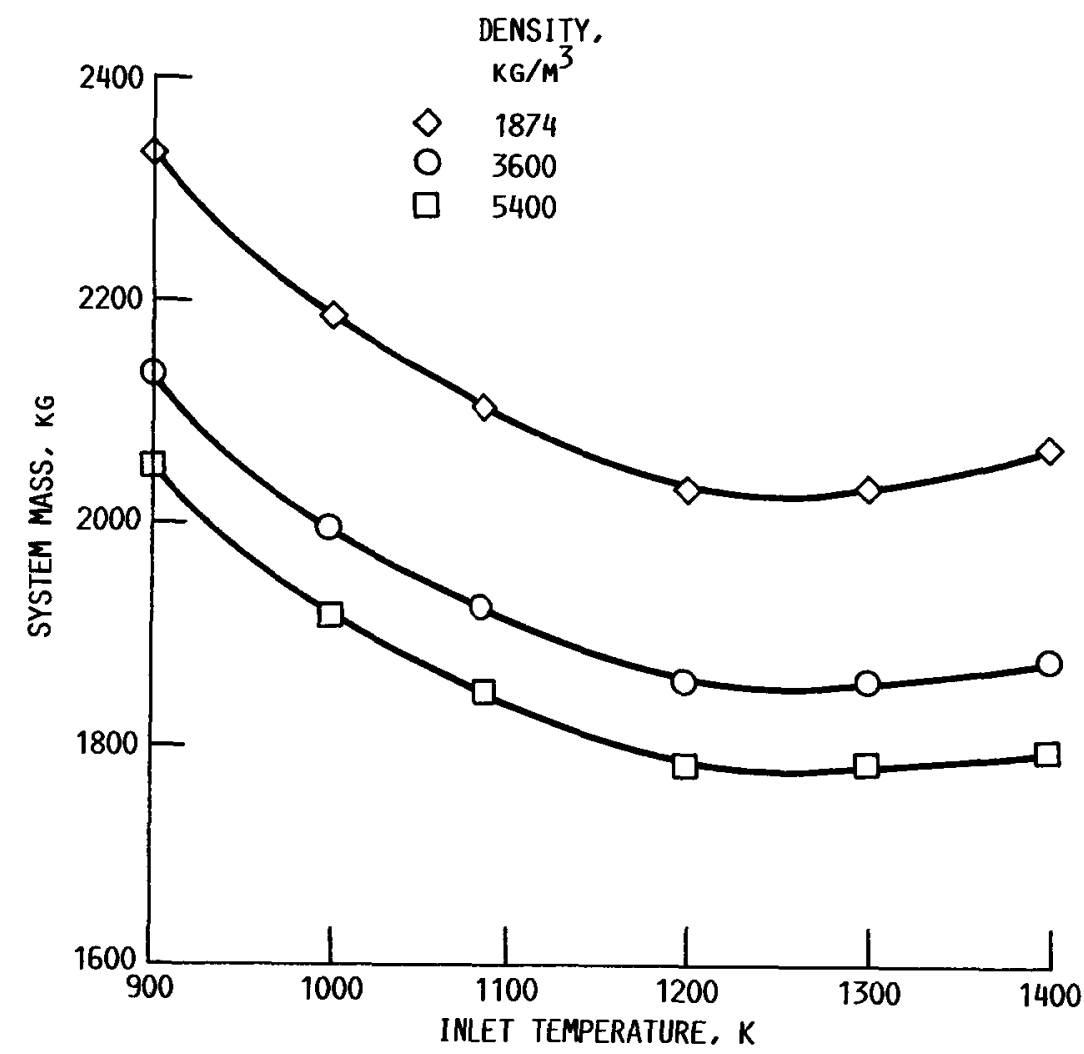

FIGURE 7. - SYSTEM MASS AS A FUNCTION OF INLET TEMPERATURE FOR A 35-KWE STIRLING SOLAR DYNAMIC POWER SYSTEM USING A SALT PCM AT VARIOUS DENSITIES. NUMBER OF TUBES, 60; NUMBER OF FINS, 6; HEAT OF FUSION, $1044 \mathrm{KJ} / \mathrm{KG}$. 


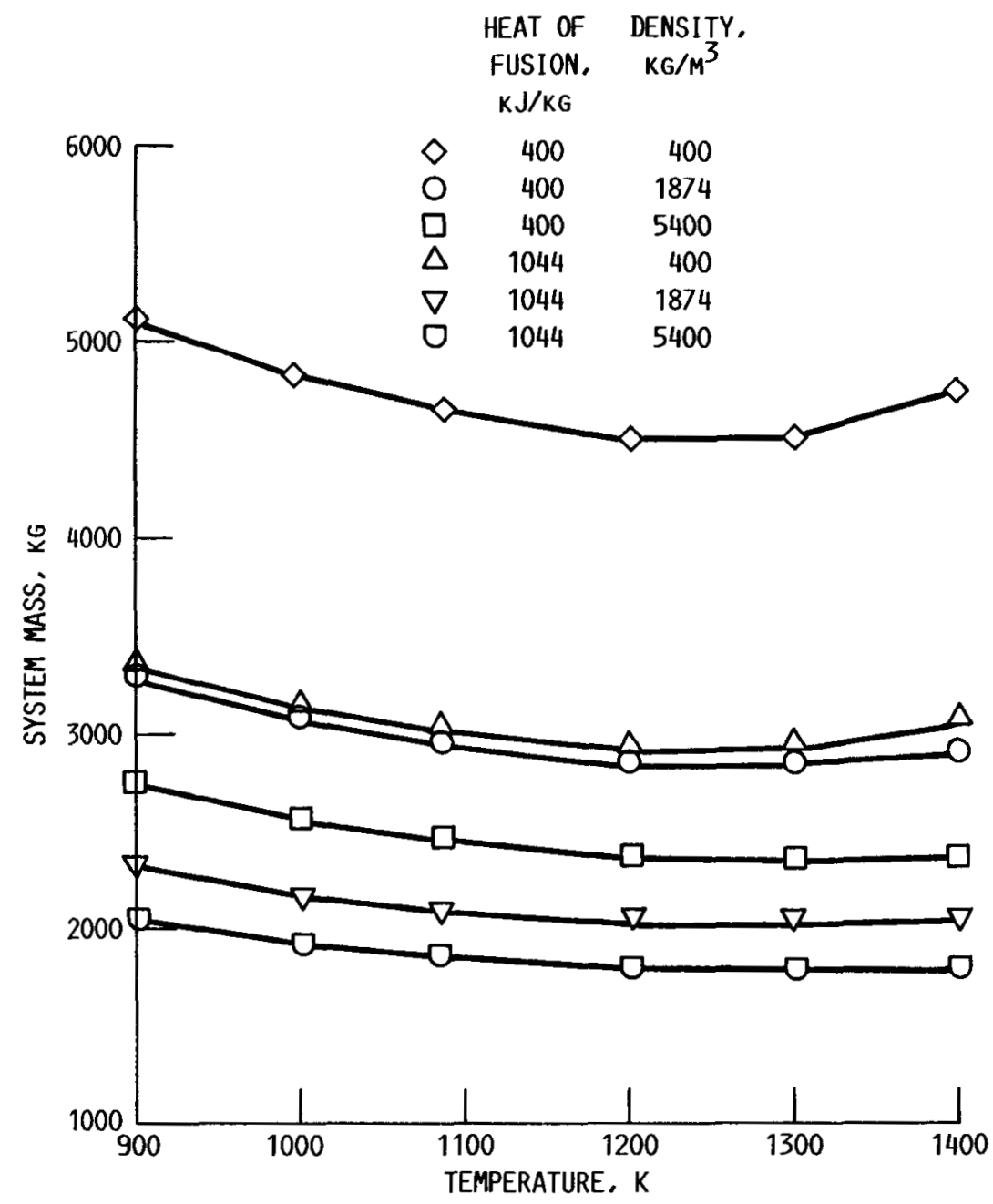

FIGURE 8. - SYSTEM MASS AS A FUNCTION OF INLET TEMPERATURE FOR A 35-KWE STIRLING SOLAR DYNAMIC POWER SYSTEM USING PCMS WITH VARIOUS HEATS OF FUSION AND DENSITIES. 


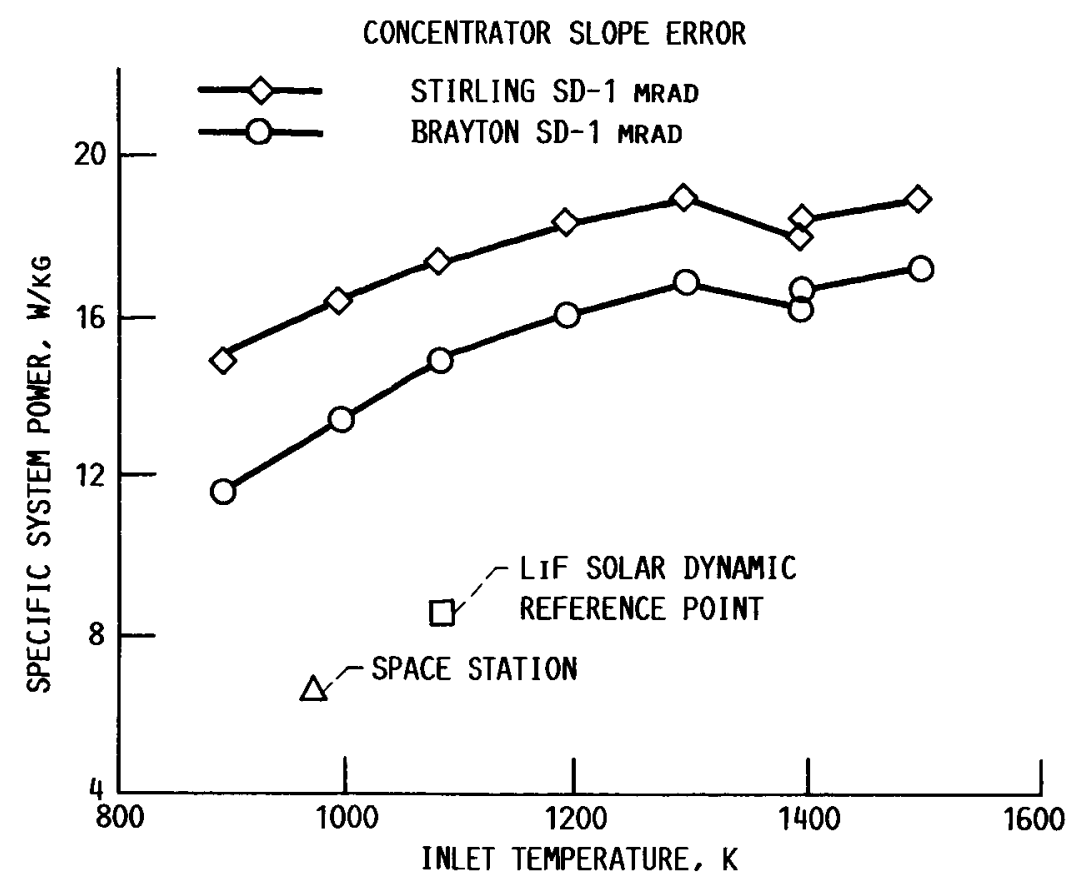

FIGURE 9. - SPECIFIC SYSTEM POWER AS A FUNCTION OF INLET TEMPERATURE FOR 35-KWE ASD SYSTEM.
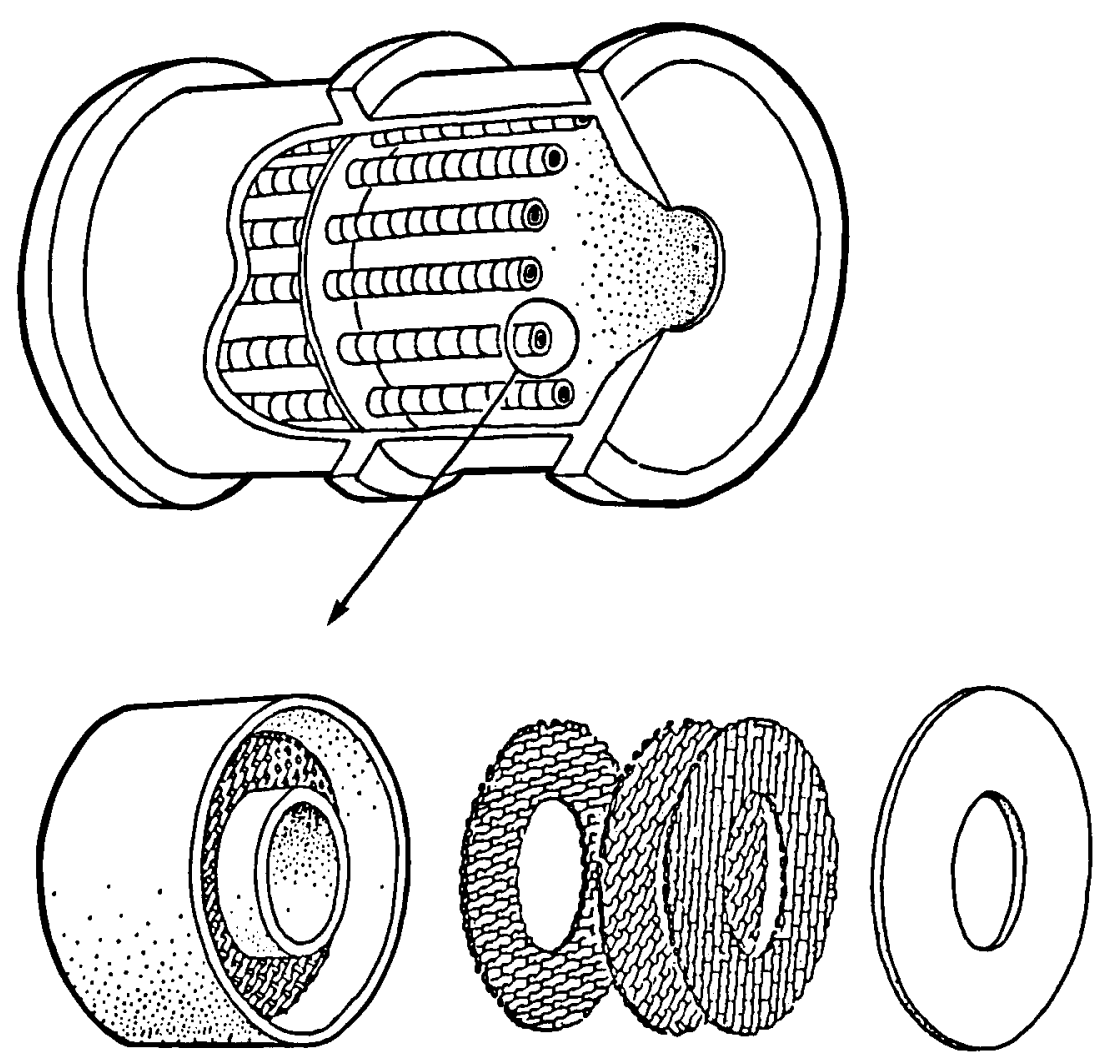

FIGURE 10. - BASELINE SOLAR DYNAMIC HEAT RECEIVER SHOWING THERMAL ENERGY STORAGE CONTAINMENT CANISTER FILLED WITH THERMALCONDUCTIVITY-ENHANCING GRAPHITE FIBERS. 


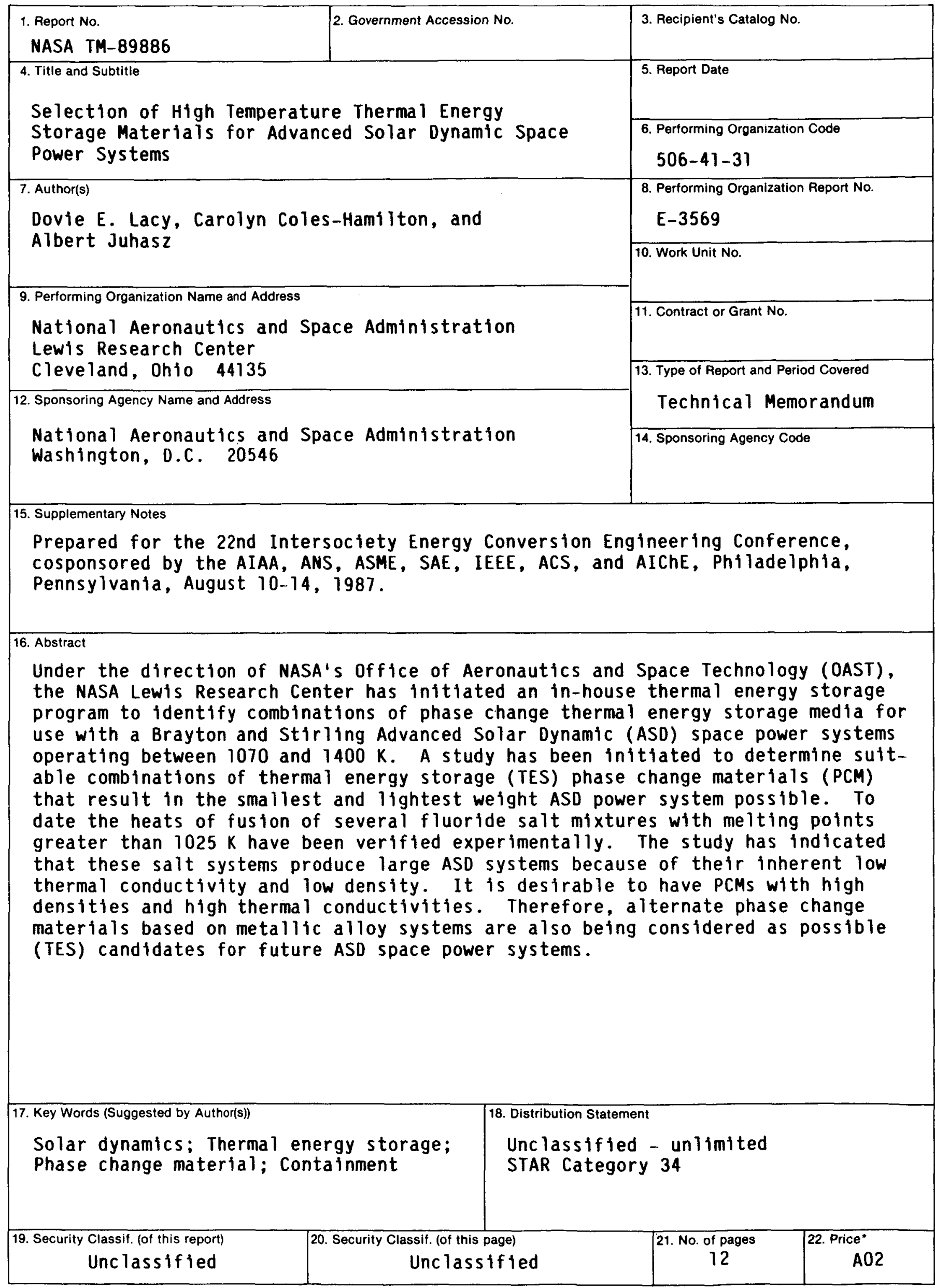

*For sale by the National Technical Information Service, Springfield, Virginia 22161 